\title{
THE REAL CONFLICT BETWEEN SCIENCE AND RELIGION: ALVIN PLANTINGA'S IGNORATIO ELENCHI
}

\section{HERMAN PHILIPSE}

University of Utrecht

\begin{abstract}
By focussing on the logical relations between scientific theories and religious beliefs in his book Where the Conflict Really Lies (2011), Alvin Plantinga overlooks the real conflict between science and religion. This conflict exists whenever religious believers endorse positive factual claims to truth concerning the supernatural. They thereby violate an important rule (R) of scientific method and of common sense, according to which (seriously disputed) factual claims should be endorsed as (approximately, probably, etc.) true only if they result from validated epistemic methods or sources.
\end{abstract}

\section{INTRODUCTION}

The question as to how science and religion are related should be of interest to all of us. Well-educated people living in the twenty-first century will endorse a world-view that is deeply influenced by the results of scientific and scholarly investigations. Can a religious creed be integrated properly into such a Weltanschauung, or, vice versa, can one incorporate all scientific results into a religious world-view? For instance, are Jewish, Christian, Muslim, or Mormon monotheistic beliefs about God and the world still intellectually acceptable in our age of science? There is no consensus concerning this issue, and the various possible answers have implications for many aspects of society and human life.

Consequently, a definitive analysis of the interrelations between science and religion developed by a major Christian philosopher deserves serious attention. In his book Where the Conflict Really Lies, published in 2011 (referred to as WCRL), Alvin Plantinga defends two complementary and thought-provoking claims, to wit: (a) 'there is 
superficial conflict but deep concord between science and theistic religion', whereas (b) there is 'superficial concord and deep conflict between science and naturalism. ${ }^{1}$ In this article, I shall contest the first conjunct of (a), that is, the thesis that there is (merely) a superficial conflict between science and theistic religion.

As I shall argue, the conflict between science and religion is profound indeed, and it is only by his narrow focus on logical conflicts that Plantinga might be able to seduce his readers into thinking otherwise. Of course, if I am right that there is a deep conflict between science and religion, that is, at least between science and theistic religion as Plantinga conceives of it, the second conjunct of Plantinga's first thesis (a) must be false as well. I also think that the second conjunct of (b), the idea that there is a deep conflict between science and naturalism, is completely mistaken, as has been argued by many critics of Plantinga, but I shall not dive into the deep waters of this brainteaser here. ${ }^{2}$

Let me start $(\$ 2)$ by commenting on one of Plantinga's arguments for the first conjunct of (a). In $₫ 3$, I develop the view that there is a deep conflict between science and traditional religion, and I explicate the term 'science' for the present context. This deep conflict raises the question as to how educated and intelligent people living in the twenty-first century can still reasonably endorse the tenets of a religion such as Christianity or Islam $(\$ 4){ }^{3}$ Contemporary religious believers have four options with regard to this issue, which I schematize as the end-nodes of a decision tree. One of these options has been developed by Alvin Plantinga as a conditional A/C (Aquinas-Calvin) model of a sensus divinitatis supplemented by an 'Internal Instigation of the Holy Spirit'. If this model were adequate, 'the full panoply of Christian belief' might amount to knowledge for (some?) Christians even in the absence of any supporting arguments, since this panoply would probably consist of warranted properly basic beliefs, at least if the Christian god exists. ${ }^{4}$ I shall argue, however, that there also is a deep conflict between this model and science in the sense in which science is properly characterized (\$5).

\footnotetext{
${ }^{1}$ Plantinga (2011: ix) (Plantinga's italics).

2 Cf., for example, Fales (1996), Beilby (2002), Plantinga \& Tooley (2008), Childers (2011), and Law (2012).

3 The central question of Plantinga was whether Christian belief is still intellectually acceptable for 'educated and intelligent people living in the twenty-first century' (2000: viii).
}

${ }^{4}$ The quote is from Plantinga (2000: 241, 357, 499). 


\section{LOGICAL CONFLICTS}

In Parts I and II of WCRL, Alvin Plantinga argues that either there is no conflict at all between science and religion, or, if there is a conflict, it is only 'weak' or 'superficial' in the sense that scientific results do not (tend to) provide religious (Christian) believers with defeaters for their beliefs. ${ }^{5}$ The notion of conflict he employs is a logical one in a broad sense: there is a 'conflict' between $p$ and $q$ if and only if $p$ contradicts $q$, or if $q$ is 'massively improbable' given $p$ and background beliefs. ${ }^{6}$ Since such logical conflicts can only obtain between (sets of) propositions, Plantinga focuses on relations between religious beliefs and scientific theories in his discussion of possible conflicts between science and religion.

More specifically, he argues that Darwinism is logically compatible with the idea of a divinely guided evolution (Ch. 1-2), that a belief in miracles is consistent both with Newtonian mechanics or classical science (Ch. 3) and with quantum mechanics (Ch. 4), and that even though there may be logical incompatibilities between Christian beliefs on the one hand and some results of Historical Biblical Criticism or explanations of religion by evolutionary psychologists on the other hand (Ch. 5), the latter do not defeat the former (Ch. 6). Let me comment on the issue of Darwinism only, in order to show that Plantinga's preoccupation with logical relations between articles of faith and scientific theories conceals from view the profound conflict between science and religion (cf. \$3).

Chapters 1 and 2 of WCRL are devoted to the question of whether there is a logical conflict between on the one hand evolutionary theory, specifically the Darwinist doctrine that the process of descent with modification is driven by the natural mechanism of (mostly) natural selection operating on heritable random genetic mutations, and on the other hand the Christian doctrine that God has created human beings in his image. ${ }^{7}$ Of course (neo-) Darwinism clearly contradicts many

${ }^{5}$ Cf. Plantinga (2011: xiii and 180) for these (slightly diverging) definitions of a weak or superficial conflict.

${ }^{6}$ Plantinga (2011: 143-4). More may be needed to make such a conflict 'interesting' (ibidem).

${ }^{7}$ Plantinga (2011: 9ff., 34ff.). Of course, chance plays a large role in the selection process as well. As Ernst Mayr (2001: 156) stresses, 'potentially favorable gene combinations are undoubtedly often eliminated by indiscriminate environmental forces such as floods, earthquakes, or volcanic eruptions before natural selection has had the opportunity to favor specific genotypes'. Furthermore, in sexual species, the major source of variation is the process of sexual reproduction. 
details of the creation stories told in Genesis, if interpreted literatim. But scientifically informed Christians have been quick to point out that the (mutually inconsistent) creation stories should not be taken literally, as theologians had argued earlier on other grounds. Plantinga approvingly quotes the Princeton theologian Charles Hodge, who wrote in 1871 that if God created plants, animals, and men, 'it makes no difference how He made them, as far as the question of design is concerned, whether at once or by a process of evolution. ${ }^{8}$ Could God not have 'guided' evolution, Plantinga suggests, by causing 'the right mutations to arise at the right time', by preserving 'populations from perils of various sorts, and so on'?' Of course one might add less pleasant speculations in a similar vein. Could God not have caused the Cretaceous-Paleogene extinction event some 65.5 million years ago, which killed off the non-avian dinosaurs, by steering a giant asteroid towards Earth? If He wanted to create man in his image, as Plantinga avers, God had good reasons for guiding the lethal asteroid towards our planet, because given the actual course of evolution, the extinction of these dinosaurs was a necessary condition for the possibility of human's evolving. ${ }^{10}$

Plantinga stresses repeatedly that there is no logical conflict whatsoever between neo-Darwinism and the thesis that God guided the evolution of life on Earth, because the thesis that evolution is undirected, unguided, non-teleological, or unorchestrated by God (or anyone else) allegedly is 'a philosophical gloss or add-on to the scientific doctrine of evolution, which does not belong to the theory itself. ${ }^{11}$ In order to evaluate this surprising claim, one should distinguish more clearly than Plantinga does between three different questions: (a) is the unguidedness-thesis part of the standard theory of neo-Darwinism (the Modern Evolutionary Synthesis)? (b) Does the existing evidence support the unguidedness-thesis? And (c): is it logically possible that given the available evidence, evolution is nevertheless directed by someone?

Concerning (a) it is surprising that Plantinga in 2011 still quotes Hodges' book of 1871. As is well known, after the publication of Darwin's

8 Plantinga (2011: 11); with reference to Hodge (1871, no page number indicated).

9 Plantinga (2011: 11; cf. pp. 16, 39-40, 46, 56, 116 \&c).

${ }^{10} \mathrm{Cf}$. on the thesis that God created man in his image, Plantinga (2011), passim, see under Imago dei in his index. And cf. for similar objections by Darwin to Asa Gray: Beatty (2006: 639).

${ }^{11}$ Plantinga (2011: xii, 39, 46, 55, 63, 308-9). 
The Origin of Species in 1859, there were many attempts to defend Darwinism from the charge that it promoted atheism. The American botanist Asa Gray argued in his Darwiniana of 1876, like Plantinga, that the theory of evolution is neutral on the question whether evolution is ultimately designed. Might the Creator not direct mutations in ways that are beneficial to a species? But in letters to Gray and in the Conclusion to his Variation of Animals and Plants under Domestication of 1868, Darwin stressed that this hypothesis is antagonistic to his evolutionary theory. ${ }^{12}$ If genetic variation could be guided in a beneficial direction, natural selection would be superfluous, so that the internal logic or economy of the theory excludes the idea that mutations are somehow orchestrated. ${ }^{13}$ By the end of the $19^{\text {th }}$ century, most professional biologists were convinced on many grounds that theistic evolutionism is a non-starter. ${ }^{14}$ Accordingly, it is a central tenet of the Modern Evolutionary Synthesis that genetic mutations occur 'by chance' or 'at random' in the sense of not being directed toward the adaptive needs of the organisms concerned or of the populations to which they belong, and that natural selection is not goal-directed either, as is stressed in contemporary textbooks. ${ }^{15}$

If this is the case, how can Plantinga seriously claim that the unguidedness-thesis is not part of neo-Darwinism but rather a 'philosophical gloss or add-on'? How can he drive a wedge between 'random' and 'unguided'? ${ }^{16} \mathrm{He}$ does so in two steps, which he buttresses by quotes from Ernst Mayr and Elliott Sober, respectively. The quote from Mayr shows that the 'randomness' of mutations does not mean that they are uncaused or 'just a matter of chance':

When it is said that mutation or variation is random, the statement simply means that there is no correlation between the production of new genotypes and the adaptational needs of an organism in a given environment. ${ }^{17}$

${ }^{12}$ Darwin (1868: 236).

${ }^{13}$ Cf. also Bowler (1989: 224): 'Darwin doubted that any theologian would want to attribute such horrors to a process directly supervised by God.' Cf. for Darwin's discussion with Gray: Beatty (2006).

${ }^{14}$ Cf. Bowler (1989: 222-226).

15 Cf. Ridley (2004: 88-89); Mayr (2001: 133-4); Simpson (1984 [1944]: 55-56); Dobzhansky et al. (1977: 66). Cf. Merlin (2010: 2ff.) for a conceptual analysis of various formulations. Plantinga (2011) quotes mainly Dawkins (p. 14) and Dennett (p. 34).

${ }^{16}$ Cf. Boudry (2012: 1).

17 Plantinga (2011: 11), and Mayr (1988: 98). 
According to Plantinga, Sober 'puts the point a bit more carefully' because he stresses that there is no natural mechanism that directs mutations in adaptive directions:

There is no physical mechanism (either inside organisms or outside of them) that detects which mutations would be beneficial and causes those mutations to occur. ${ }^{18}$

From these quotes Plantinga concludes correctly that the mutations being 'random in that sense is clearly compatible with being caused by God.' ${ }^{19}$ However, it does not follow, and is in fact contradicted by the quote from Mayr (unless one restricts the meaning of this quote $a$ Sober to the absence of physical guiding mechanisms), that randomness in the evolutionary sense is also logically compatible with being guided by God, if at least 'guided' means that mutations are somehow directed towards new adaptations, or to the development of new species. And what else should it mean?

Clearly, then, the thesis that evolution is unguided is an integral part of the Modern Evolutionary Synthesis, and Plantinga's argument to the effect that the thesis is 'a philosophical gloss or add-on' to this theory is a non-sequitur. ${ }^{20}$ As Mark Ridley stresses in his textbook on evolution, ' $\mathrm{i}] \mathrm{t}$ is one of the most fundamental claims in the Darwinian theory of evolution that natural selection is the only explanation for adaptation.' ${ }^{21}$

Concerning (b), the issue as to whether the existing evidence supports the thesis that mutations are random, not in the sense of 'uncaused' but in the sense of 'unguided to future adaptation', one should admit that the empirical evidence supporting this claim is overwhelming, and that it is sensible to generalize from such consistent findings. ${ }^{22}$ Yet this randomness thesis cannot mean that, for example, specific types of mutations all have the same probability of being beneficial, deleterious,

18 Plantinga (2011: 12), with reference to Sober, 'Evolution Without Metaphysics?', probably the draft of 'Evolution without Naturalism', in Jonathan L. Kvanvig, ed. (2011: 187-221) (no date or page indicated by Plantinga).

${ }^{19}$ Plantinga (2011: 12) (last italics mine).

20 This is the consensus view, as Plantinga (2011: 12) admits; cf. Merlin (2010) for a defence of this view against scientific critics. Cf. Monton \& Gage (2012) for another criticism of Plantinga's argument. One should diagnose Plantinga's fallacy as a fallacy of ambiguity, because he confuses 'uncaused' with 'unguided'.

${ }^{21}$ Ridley (2004: 256) (my italics). Ridley explicitly excludes theistic explanations.

${ }^{22}$ Cf. Merlin (2010) for an overview and answers to criticisms based on the discovery of mutator mechanisms. 
or neutral. For example, small genetic mutations have a greater chance of being adaptive than larger ones, which tend to be deleterious or lethal, as Sir Ronald Fisher showed mathematically. ${ }^{23}$ Furthermore, new adverse environmental conditions, such as temperature change, might cause a global increase of mutation rate, thereby also increasing the probability that beneficial mutations occur within a given period. And the probability of mutations of different types is unequal both across the genome and at a particular genomic site. No genetic mutation is random in the mathematical sense that it is equally probable as any other genetic mutation or no mutation. What the randomness thesis does mean is that 'there is no specific causal connection between the probability of a mutation being beneficial (in a given environment) and the probability of it occurring (in this environment) ${ }^{24}$

As regards (c), it is trivially true that because our evidence is limited in principle, it is always logically possible that there are hidden variables, which are still undetected or even undetectable. For example, our available evidence concerning the Cretaceous-Paleogene extinction event does not contradict the hypothesis that God caused it by steering an asteroid towards Earth. But why should we accept such a gratuitous speculation? A mere logical possibility does not warrant a factual assertion, and if someone claims that he knows this by means of an 'Internal Instigation of the Holy Spirit', we should respond with a shrug. This appropriate reaction directs our attention to the really profound conflict between science and religion, which is not (primarily) a conflict in the narrow logical sense of a contradiction or a low likelihood, as I shall argue in section 3.

Finally, combining issues (a) and (c) one might even show that in a sense there is no contradiction between neo-Darwinism and the theistic doctrine of guided evolution, in spite of the fact that Plantinga's own argument to this effect is a non sequitur. ${ }^{25}$ Even though mathematical models of evolutionary processes concerning changes in trait frequency may look deterministic if one assumes that they are applied to infinite populations, all real populations are finite. As a consequence, neo-Darwinism, if conceived of merely as a set of such mathematical models or equations, becomes a probabilistic theory when

${ }^{23}$ Fisher 1999 [1930], referred to by Merlin (2010: 4).

${ }^{24}$ Merlin (2010: 6).

25 The argument that follows in the main text has been developed in detail by Sober (forthcoming). Cf. also Sober (2010) and (2011), Chapter 4. 
applied to real populations. Instead of predicting what will happen in the future given a description of the present state of a population, the models assign probabilities to different scenarios. And since these probability statements (likelihoods) may be true even though their antecedents do not provide causally complete descriptions of populations and their ecological niches, they do not logically exclude the presence of causally relevant factors that are 'hidden' in the sense that they are not mentioned in the applied mathematical models of evolutionary theory. Of course, this argument holds for any probabilistic theory, and Plantinga uses a similar argument for the conclusion that there is no contradiction between quantum mechanics and the thesis that miracles have occurred. ${ }^{26}$ In other words, Plantinga might correctly claim that in a sense there is no contradiction between neo-Darwinism (that is: between the mathematical evolutionary models as applied to finite populations) and the thesis of guided evolution, even though in the ordinary sense of neo-Darwinism his claim is clearly false. ${ }^{27}$

This result leads us to the central question of this paper. Would the thesis that there is no contradiction between neo-Darwinism (in the sense just explained) and the doctrine of divinely guided evolution imply that at this point there is no profound conflict between science and religion? Let us generalize our query. Suppose that there is no contradiction or other logical conflict between any scientific theory that we now endorse on the basis of the existing evidence on the one hand, and the central doctrines of a specific religion such as Christianity, provided that the latter are interpreted properly, on the other hand. Does this really show that there is no profound conflict between science and Christianity? In other words, are logical relations of incompatibility (contradiction, or improbability of $p$ given $q$ and background beliefs) the only or even the main kinds of conflict that are relevant here? As I shall argue in the next section, the deep conflict between science and religion lies elsewhere, so that Plantinga's nearly exclusive preoccupation with logical conflicts amounts to an ignoratio elenchi.

26 Plantinga (2011: 92ff.).

${ }^{27}$ I would argue, however, that neo-Darwinism is more than a set of equations. Sober's motive for developing the argument I just summarized is that he wants 'to take the heat off evolutionary theory'. As he says, 'The more evolutionary theory gets called an atheistic theory, the greater the risk that it will lose its place in public school biology courses in the United States' (Sober, forthcoming: p. 15 of the manuscript). 


\section{THE REAL CONFLICT}

In order to detect where the profound conflict between science and religion really lies, an historical perspective on their interrelations from the scientific revolution in the $17^{\text {th }}$ century onwards is instructive. One arbitrarily selected example will show what I mean. ${ }^{28}$

During the 16th and 17th centuries, numerous European scholars attempted to calculate on the basis of biblical chronologies when exactly the 'beginning' had been in which God created 'the heavens and the earth. ${ }^{29}$ The challenging textual and mathematical complexities of this endeavour explain the fact that the results they published diverged considerably. Some 200 or more substantial publications appeared, and their estimates of the year of the Earth's (or the world's) divine creation varied between $6000 \mathrm{BC}$ and $2700 \mathrm{BC}$. For example, whereas Heinrich Bullinger (1504-1575) concluded that the Earth started to exist in 3004 BC, Thomas Allen (1608-1673) argued in his 1659 book A Chain of Scripture Chronology that its creation took place in 3934 BC. As William Nisbit observed in A Scripture Chronology of 1655, there was 'great disagreement among chronologues in counting the years from the Creation of the World to the death of our Saviour'. Nevertheless, the scientific community of biblical chronologists agreed that 'The Sacred Writ is the best Register' for calculating the age of the Earth or the world, as Allen wrote in his preface. ${ }^{30}$

Today the age of the Earth is estimated to be $4.45 \pm 0.05$ billion years on the basis of evidence from radiometric age dating of meteorite material, which matches the ages of the oldest-known terrestrial and lunar samples. A more precise estimate is difficult to obtain, because the accretion time of planet Earth is unknown. Furthermore, the age of our universe, defined as the time elapsed since the postulated Big Bang event, is estimated $13.798 \pm 0.037$ billion years within the Lambda-CDM concordance model on the basis of various types of measurements, such as measurements of the microwave background radiation and measurements of the expansion rate of the universe. ${ }^{31}$ For at least two reasons no well-informed intellectual will resort nowadays to biblical chronology in order to determine the age of the Earth or of our universe.

\footnotetext{
${ }^{28}$ Plantinga (2011: 10) discusses this example briefly.

${ }^{29}$ Genesis 1:1-19.

${ }^{30}$ Cf. for these data and quotes: Jackson (2006: 13-29).

${ }^{31}$ Estimate of 22 March 2013.
} 
First, in and after the $17^{\text {th }}$ century Western scholars discovered other alleged religious revelations, on the basis of which very different ages of the Earth or the universe might be calculated. For example, according to calculations informed by the Vedas, the current age of our universe would be in the order of magnitude of 155.5 trillion years. But if allegedly revealed religious texts contradict each other on specific topics, and if there are no good epistemic reasons to prefer one to the others, we should conclude that they aren't reliable sources of knowledge concerning these topics, such as the time of divine creation, or the existence of specific gods.

Secondly, a great many empirical discoveries and theoretical developments in scientific disciplines such as geology, physics, biology, archaeology, and astronomy produced a consilience of inductions to the effect that both the Earth and our universe are much older than biblical calculations suggested. The discovery of radioactivity by Bequerel and others around 1900 enabled scientists to resolve the well-known contradiction between the calculation of the age of the solar system and the Earth on the basis of thermal gradients by Lord Kelvin on the one hand, and estimates of the time-span of the biological evolution on the other hand. ${ }^{32}$ Moreover, this discovery enabled physicists to develop reliable methods for calculating the age of rocks on the basis of knowledge concerning the radioactive decay of radioactive isotopes.

Reflecting on the history of the sciences from the $17^{\text {th }}$ century onwards, taking this and myriad other examples into account, philosophers of science have attempted to characterize science in contradistinction to other cultural phenomena such as religion. Clearly, we should not define science in terms of specific scientific theories, because theories are fallible and may be superseded by better ones in the course of scientific progress. Rather, science (in the broad sense of the German Wissenschaft, including historical research and other areas of scholarship) should be defined in methodological terms, as the search for factual truth by utilizing the best validated truth-conducive methods available at a time. ${ }^{33}$

${ }^{32} \mathrm{Cf}$. Jackson (2006), Chapters 11, 13. Plantinga raises the temporal constraint problem for the evolution of the eye (2011:23), but he mentions neither the interesting history of the problem nor relevant contemporary literature, such as Nilsson \& Pelger (1994).

${ }^{33}$ Whether science can be defined as a search for true general theories is another matter. Cf. Rowbottom (2010). Cf. also the extensive debate on Van Fraassen's Constructive Empiricism. Furthermore, if normative statements are truth-apt, we should exclude ultimate moral norms etc. from this definition. 
Scientific method can be specified at various levels of abstraction in terms of sets of norms for correct epistemic procedures. At the highest level of abstraction, philosophers have attempted to specify rules of method that hold for all scientific and scholarly disciplines, while at the lowest level of particular topics of research, scientists will specify norms for the proper application of specific instruments or techniques, which typically are theory-laden. The general definition of science as the search for factual truth by utilizing the best validated truth-conducive methods available, might be elaborated by specifying rules at the highest level of abstraction.

In the context of this article, it will suffice to formulate one of these epistemic rules only, which, I propose, should be part of an elaborated characterization of science:

$\mathrm{R}(\mathrm{ule})$ : Claims concerning specific disputed facts should be endorsed as (approximately, probably, etc.) true only if they are sufficiently supported by the application of validated methods of research or discovery.

Furthermore, one might specify in part what may be called a 'scientific attitude' (in the broad sense) by the following necessary condition:

$S$ (cientific attitude): An individual has acquired a scientific attitude only if (s)he applies rule $\mathrm{R}$ to factual claims that are of importance for her/

him, or relies on testimonies of experts who applied rule R.

A few observations on validation will be useful in order to elucidate rule $\mathrm{R}$. In some cases, the validation of methods of the search for truth is relatively easy, but in other cases, such as the validation of methods for calculating the age of rocks on the basis of knowledge concerning the radioactive decay of radioactive isotopes, validation is complex: it may take years and require the cooperation of many experts. But in general, there are at least three maxims to be applied in the validation of particular methods of research.

First (maxim 1), repeated and mutually independent applications of one and the same method should yield consistent and informative results. Second (maxim 2), one should test whether various detection methods or instruments using different techniques yield the same result if applied to the same issue. This validation test is based upon an argument from coincidence. If very different processes of research, which have not much in common, produce identical results, it would be an unlikely coincidence if these results were artefacts of the methods or instruments rather than containing information about the item under 
investigation. Finally (maxim 3), in the case of theory-laden methods and techniques, theoretical understanding of these methods and techniques may contribute decisively to (de-) validation, and of course the relevant theories should be well confirmed by various types of evidence. ${ }^{34}$

We may now define the profound conflict between science and religion as follows:

$\mathrm{C}$ (onflict): Adherents of religions, to the extent that they endorse positive factual claims to truth concerning supernatural entities such as gods, hell, heaven, angels, ghosts, immortal souls, etc., violate rule R, because typically these claims are not sufficiently supported by the application of validated methods of research or discovery.

Thesis $\mathrm{C}$ explains why most of us who really have acquired a scientific attitude, so that they satisfy $S$, will not endorse any positive assertion concerning the supernatural. They will feel strongly that such endorsements would violate their ethics of belief. Of course, there are many aspects of religions apart from creeds or clusters of beliefs, such as rituals, architecture, forms of art, social organizations, dietary prescriptions, and moral norms, which may be valuable even if their creeds do not satisfy rule $\mathrm{R}$. However, while the profound conflict $\mathrm{C}$ is primarily concerned with the doctrinal aspect of religions and its epistemic sources, it will also undermine these other aspects to the extent that the former underpin the latter.

Religious apologists often claim that we should not compare the ways of acquiring their truths with scientific methods of research, because these ways are unique and differ essentially from scientific method. ${ }^{35}$ But at the lowest level of abstraction, epistemic methods of discovery are essentially different in each scientific or scholarly sub-discipline as well. For example, physical methods for measuring the temperature in the centre of the Sun are completely different from scholarly methods for detecting interpolations in ancient texts. So it will not help religious believers to stress that the ways of acquiring their truths are completely different from methods in scientific sub-disciplines. From the point of view of rule $R$, the crucial question is whether these religious ways of acquiring truths can be validated.

\footnotetext{
${ }^{34}$ Cf. Philipse (2012), $\$ 6.2$, and Hacking (1983), Chapter 11.

${ }^{35}$ Cf. Plantinga (2011: 123-4): there would be a conflict 'only if science tells us that beliefs in all the areas of our epistemic life ought to be formed and held in the same way as scientific beliefs typically are. But of course that isn't a scientific claim at all; it is rather a normative epistemological claim, and a quixotic one at that'.
} 
What are the particular ways of acquiring (allegedly) true insights in the case of specific religions? The list is open-ended, but on the basis of scriptural analysis and anthropological research we should at least mention alleged revelations, such as the Bible, the Vedas, or the Book of Mormon, the variety of religious experiences, alleged graces of gods, the interpretation of signs or signals or sacrifices, the averred effects of prayer, various kinds of ascetism such as fasting forty days in a desert, which may produce particular experiences, hearing voices in the absence of other human beings, a plethora of rituals, and humbly engaging in religious communities or practices. ${ }^{36}$

My contention is that none of these religious ways of discovering or receiving the truth has been validated, so that those who still endorse positive religious factual claims to truth on their basis violate rule R. Even worse, it has been shown conclusively with regard to all of these ways that in general they are unreliable. For example, the various revelations that people pretend to have received from their god(s) contradict each other at many points (cf. maxim 1, above). Beliefs that once were accepted on the basis of a revelation, such as the conviction that God created the Earth between 6000 and 2700 B.C., have been refuted by scientific research (cf. maxim 2). And the phenomenon of hearing voices in the absence of others, which occurred to important founders of religion such as Paul or Mohammed, and which at the time could perhaps not be interpreted otherwise than as being due to the activity of invisible spirits or gods, is now accounted for within a different and more scientific framework as typically being a symptom of temporal lobe epilepsy, psychosis, schizophrenia, and other mental illnesses (cf. maxim 3), so that its religious importance has been disconfirmed. ${ }^{37}$

The example of biblical chronology shows well why the logical relations between scientific theories and articles of faith cannot be the main locus of the conflict (if any) between science and religion, although this is Plantinga's focus in WCRL. Admittedly, many religious convictions based upon biblical texts, such as the doctrine of special creation still defended by William Paley in his Natural Theology of 1802, have been refuted by later scientific research. In all these cases, contradictions play a role, because the religious conviction is contradicted (or rendered

\footnotetext{
${ }^{36}$ Cf. for a recent defence of this last option: Moser (2010).

37 Cf. Philipse (2012), chapters 1 and 6.3 for a more extended argument with references to scientific and scholarly literature. Incidentally: this is not a genetic fallacy; the underlying structure of the argument is Bayesian.
} 
improbable) by the relevant scientific theory or result. But the majority of those who want to retain their religion will remove the contradiction by re-interpreting the relevant religious source, so that in many cases scientific progress has set the agenda for Biblical re-interpretation. ${ }^{38}$ Although fundamentalist creationists may stick to biblical chronology, more sophisticated Christians re-interpret the relevant biblical passages as figurative or as myths. ${ }^{39}$

Let me round off this section by three comments. The first is concerned with the issue of defeaters. How can one defend the view that well-confirmed results of scientific research will not amount to defeaters for elements of 'the full panoply of Christian belief in all its particularity', if one also acknowledges that scientific progress has set the agenda for biblical reinterpretation? An enlightened Christian such as Alvin Plantinga seems to be confronted by a tension or even a contradiction at this point. I shall come back to the issue in section 5 .

Second, one might object to rule $\mathrm{R}$ that we all accept many factual beliefs which do not result from using validated methods of research or discovery, and that this is not only perfectly reasonable but also unavoidable. For example, what about the factual beliefs that we endorse on the basis of perception or testimony? Can we avoid assuming certain principles of credulity as fundamental principles of rationality, such as the rule that one is justified in believing what one takes oneself to perceive or have perceived unless there are defeating considerations? ${ }^{40}$ Surely, if all of us violate rule $\mathrm{R}$ continuously in daily life, it cannot be a valid objection to religious believers that they do so in endorsing their religious beliefs.

I would argue, however, that although it is true that we cannot but start with a weak trust in our elementary epistemic sources, we are

${ }^{38}$ As is well known, re-interpretation may take some time. Heliocentrism contradicted many biblical texts in a literalist interpretation, such as 1 Chronicles 16:30, Psalm 93:1, Psalm 96:10, Psalm 104:5, Ecclesiastes 1:5, and, notably, Joshua 10:13. However, Copernicus's De Revolutionibus and Galileo's Dialogues did not disappear from the Catholic Index before 1835. And it was only in 1992 that a pope (John Paul II) finally vindicated Galileo (L'Osservatore Romano N. 44 (1264) - November 4, 1992).

${ }^{39}$ One might justify this necessity of continuous Biblical re-interpretation by stressing that a divine message is very difficult to interpret. Cf. Plantinga (2000: 383): ' [g]iven that the Bible is a communication from God to humankind, a divine revelation, there is much about it that requires deep and perceptive reflection, much that taxes our best scholarly and spiritual resources to the utmost.'

${ }^{40}$ Cf. Swinburne (2004: 303 ff.), and Philipse (2012: 317, note 23). 
validating them continually by applying implicitly the three maxims for validation mentioned above, so that usually our initial trust increases and is legitimized. For example, consecutive visual perceptions of the same thing confirm each other (maxim 1). When we move around in the world, our tactile perceptions typically corroborate the visual ones, and if they do not, we test our eyes (maxim 2). Finally, scientific understanding of light and sound explains that we hear a distant collision later than we see it, for instance (maxim 3 ). We also continually and implicitly test our sense modalities by comparing what we perceive with what others observe, and the same holds for testimony, memory, and so on. Whenever our particular factual claims about the world are seriously disputed, we validate our sources explicitly. In short, our legitimate use of our senses, and our proper reliance on testimony or memory, is not an exception to rule R. ${ }^{41}$

Finally, it is often claimed that scientific methodology, including rule $\mathrm{R}$, only applies to the natural universe, and not to the supernatural. The idea is that apart from the usual rules of method at the highest level of generality, there is yet another self-imposed constituting principle of science in a broad sense, which is called methodological naturalism. According to the doctrine of methodological naturalism, a theory can be called 'scientific' only if it does not postulate supernatural entities, and by definition neither the data set nor the background knowledge used in testing scientific theories can include references to the supernatural. ${ }^{42}$ If this conception of science were correct, one might aver that rule $\mathrm{R}$ does not apply to factual religious beliefs, because it is part of scientific methodology, which is naturalistic by definition.

However, as has been pointed out by many critics of this doctrine, naturalism is not an intrinsic constitutive principle of science, but rather a generalized result of many ages of scientific research, which is supported by an overwhelming consilience of inductions. ${ }^{43}$ Again and again, explanatory hypotheses that postulated supernatural entities or effects of supernatural agents have been superseded by superior natural

${ }^{41}$ Cf. Philipse (2012: 319). Incidentally, I would not consider the philosophical view of direct realism concerning sense perception (which I endorse) as such a 'particular factual claim', whereas a hypothesis of a deceiving demon (or brain surgeon) would be one. Hence, philosophical realists concerning sense perception do not violate rule $\mathrm{R}$, whereas radical sceptics would do so.

${ }^{42}$ Cf. Plantinga (2011: 168-174).

${ }^{43}$ Cf. Boudry et al. (2010); Coyne (2009); Sober (2011), Ch. 4. 
explanations. To mention just one notorious example, the Newtonian assumption that the so-called Jupiter/Saturn problem of the stability of the solar system had to be solved by postulating divine interventions was brilliantly refuted by Laplace in 1786, when he solved the problem by subtle gravitational calculations. ${ }^{44}$ Given this consilience of inductions, scientists rightly concluded that it would be a waste of time to try out supernatural explanations again. To the extent that methodological naturalism is a norm of scientific method at all, it is a rule justified by empirical lessons of the past.

I have argued in this section that by focussing on (alleged) logical conflicts between scientific theories or results and Christian doctrines, Plantinga overlooks the deep conflict between science and religion, which is concerned with the issue as to whether ways of discovering factual truths can be validated. ${ }^{45}$ This deep conflict consists in the fact that religious believers, to the extent that they endorse positive factual claims to truth concerning the supernatural, violate rule R. Can they avoid this conflict, or somehow resolve it?

\section{A DECISION TREE FOR THE FAITHFUL: PLANTINGA'S OPTION}

The spectacular scientific and scholarly progress during the last four centuries confronts religious believers with a crucial problem. Because of its superior methods in the search for truth, science has displaced religion in most domains of modern life, such as medicine and psychiatry. Furthermore, the domain-specific alleged sources of truth of religions could not be validated, and their reliability has been contested on many grounds. How, then, can 'educated and intelligent people living in the twenty-first century' still reasonably endorse a religious creed ${ }^{46}$

In their attempts to answer this question, contemporary philosophers of religion have developed an impressive variety of apologetic strategies, which may be classified under four main options. By schematizing these

${ }^{44}$ Cf. Hahn (2005), Chapter 5.

${ }^{45}$ At the end of his fourth chapter, Plantinga mentions 'a couple of other allegations of conflict between science and religion', admitting that he doesn't 'have the space to do them justice', although he indicates how his 'reply to them might go' (2000: 122). He briefly discusses John Worrall (2000), whose analysis of the 'irreconcilable' conflict between science and religion resembles mine to some extent. Plantinga's brief criticisms of Worrall are either inadequate or do not apply to my account.

46 Plantinga (2000: viii). 
options as the end-nodes (b, d, e, and $\mathbf{f}$ ) of a decision tree, which consists of three interlocked dilemmas, we see that they exhaust all logical possibilities. First, a religious believer might either (a) endorse a cognitive interpretation of (at least some parts of) a religious creed, and hold that religious statements such as 'God created us in his image' are factual truths, or (b) prefer a non-cognitive interpretation, according to which the relevant religious creed does not contain any positive factual claim to truth concerning the supernatural. Second, the religious believer who opts for (a) in the first dilemma might endorse either (c) evidentialism, the view that convincing evidence and arguments are needed in order to endorse reasonably a religious claim to truth, or (d) the negation of evidentialism, according to which such evidence or arguments may not be necessary. Finally, those who accept (c) might hold that from a (methodo-) logical point of view the evidence and arguments that may justify a religious claim to truth are either (e) completely different from scientific arguments, or (f) similar to scientific arguments, for example because they can be formulated in terms of Bayes' theorem. ${ }^{47}$

Those who opt for end-node (b), whether developed as Stephen Jay Gould's NOMA thesis or by (re-) interpreting the 'deep grammar' of the religious language game à la $\mathrm{D}$. Z. Phillips, will not violate rule $\mathrm{R}$, because they do not endorse any religious claim to factual truth. ${ }^{48}$ However, they pay a high price for this advantage of instant immunization against factual criticisms. By eliminating all factual claims concerning the supernatural from their creed, they will be at a loss to explain what can legitimize their 'magisterium' of religious meaning and values. One may sympathize with religious apologists such as Plantinga, then, who prefer (a) because they want to be religious believers in a substantial sense.

By opting for (a), Plantinga is landed in the second dilemma between evidentialism (c) and its denial (d). As is well known, Plantinga not only criticized incisively various versions of evidentialism in his works from his 1982 paper 'The Reformed Objection to Natural Theology' onwards, an endeavour that culminated in his summa Warranted Christian Belief of 2000. He also holds that (argumentative) evidentialism as an apologetic strategy is bound to fail. As he says, 'I don't know of an argument for Christian belief that seems very likely to convince one who doesn't

${ }^{47}$ Cf. Philipse (2012) for a critical analysis of the most promising philosophical elaborations of each of these options.

${ }^{48}$ Cf. Gould (1999) and Phillips (2005). 
already accept its conclusion. ${ }^{39}$ I presume that he would say the same thing with regard to cumulative case strategies of arguing for theism, such as Richard Swinburne's. Consequently, Plantinga chose to develop end-node (d) of the decision tree for religious apologists.

According to Plantinga's version of (d), 'the full panoply of Christian belief, including trinity, incarnation, atonement, resurrection' can, 'if true, have warrant, can indeed have sufficient warrant for knowledge' without being supported by any evidence or arguments, because it might consist of properly basic beliefs. ${ }^{50}$ In order to show that this can be the case, Plantinga developed his 'Aquinas/Calvin' or A/C model of religious knowledge, according to which God, if he exists, probably has implanted in all human beings a specific epistemic module, the sensus divinitatis, which, if functioning properly, gives us the relevant religious knowledge in the basic way, that is, without the need for evidence or arguments.

Since Plantinga's model is 'epistemically possible' only if its description is consistent with everything we know, he has to extend the model in such a way that it accounts for the fact that most humans have not been, and are not, believing Christians. ${ }^{51}$ In his (2000), Plantinga does so by incorporating some Christian dogmas into the model, such as original sin, which has 'ruinous cognitive consequences', and salvation by Christ. ${ }^{52}$ Indeed, Plantinga avers that by an 'Internal Instigation' the Holy Spirit might seal the gift of faith upon the hearts of (some?) Christians, while nonbelievers suffer from the cognitive consequences of original $\sin .{ }^{53}$ Let us now wonder whether Plantinga's theory of religious knowledge enables him to avoid, or resolve, the various conflicts between science and religion.

\section{THE CONFLICT IS NEITHER AVOIDED NOR RESOLVED}

In order to investigate whether Plantinga succeeds in resolving the conflict between science and religion, two sub-questions should be addressed, on the assumption that Plantinga's externalist model of religious knowledge is an adequate one. First (1), can religious believers legitimately neutralize scientific defeaters of their beliefs, so that logical conflicts between

\footnotetext{
49 Plantinga (2000: 201).

50 Plantinga (2000: 357).

${ }^{51}$ Plantinga (2000: 168-9) (Plantinga's italics).

52 Plantinga (2000: 205) (Plantinga's italics).

${ }^{53}$ Plantinga (2000: 206 and passim).
} 
science and religion are only 'weak' in the sense defined in $\$ 2$ ? Second (2), can religious believers avoid violating rule $\mathrm{R}$, so that the deep conflict between science and religion as defined in $\$ 3$ is removed?

Concerning sub-question (1), it will be obvious to most of us that religious believers cannot, and indeed have not, neutralized wellestablished scientific defeaters of their beliefs. Take, for example, the traditional Christian belief that God created all species as they are now (special creation). From the $17^{\text {th }}$ century onwards, the accumulating data of the fossil record, combined with geological knowledge and much later with various scientific dating methods, showed convincingly that evolution is a fact, and that species developed over time by descent with modification. Accordingly, this immense reservoir of evidence contradicts the traditional Christian view, and constitutes a rebutting defeater for an element of the 'full panoply of Christian belief'. Christians may, and indeed have, removed this defeater by reinterpreting their creed (cf. \$2). But this merely shows that even in their eyes scientific methods are more reliable than, for instance, a divine revelation as interpreted by theologians. How can one still trust one's belief that, for example, God created humans in his image, or that Christ was resurrected, if such beliefs are produced by a source, a revelation as interpreted by theologians, that proved to be unreliable so many times?

Given these considerations, the reader will be interested to learn how Plantinga argues for the opposite view. As he says, 'science that produces theories incompatible with Christian belief [...] would certainly not constitute a defeater for Christian belief. ${ }^{54}$ His argument goes as follows. First, using an allusion that may escape secular readers, Plantinga calls scientific theories incompatible with Christian belief 'Simonian science. ${ }^{55}$ Second, he argues that Simonian science is based upon methodological naturalism, at least in typical cases. This means not only that properly scientific explananda, or the data set to be explained, cannot contain

54 Plantinga (2011: 174, cf. 177).

${ }^{55}$ Plantinga (2011: 164, 173-5, 186-9, and passim). Officially, the expression 'Simonian science' alludes to Herbert Simon, who explained the altruistic behaviour of Mother Teresa and other Christian saints with reference to the hypothetical mental mechanisms of 'docility' and 'bounded rationality' (cf. Plantinga 2011: 134-6). But I suspect that the adjective 'Simonian' also refers to Simon the magician of Acts 8:1-24, who converted to Christianity although his heart was 'not right before God', as Peter said (vs. 21), or perhaps to Simon the Leper (Matthew 26:6-13 and Mark 14:3-9), who according to some was healed from his leprosy by Jesus. 
supernatural entities, and that the explanans, or the explaining theory, should not postulate such entities either, but also that the set of relevant background beliefs with reference to which we determine the prior probability of our explanations, cannot contain religious beliefs. ${ }^{56}$ Plantinga calls the set of these background beliefs the 'evidence base' of an explanation. ${ }^{57} \mathrm{He}$ then argues that in cases of Simonian science, the scientific theories that contradict Christian beliefs may have a very high prior probability given the scientific evidence base, but that this prior probability might be very low given the evidence base of the Christian, which incorporates the full panoply of Christian belief. And if the prior probability of Simonian theories will be very low given the evidence base of Christians, such theories cannot constitute defeaters for Christian beliefs. As Plantinga says:

I submit that the same goes for Simonian science and Christian belief. The evidence base for Simonian science (...) is part of the Christian's evidence base, but only part of it. Hence, the fact that Simonian science comes to conclusions incompatible with Christian belief doesn't provide the believer with a defeater for her belief. ${ }^{58}$

Of course, it would be absurd to argue that scientific discoveries could never defeat any of the supernatural beliefs held by Christians. For example, Plantinga admits that scientific results and methods have refuted the view that God created the Earth a few thousand years BCE. He avers, however, that this view is 'not part of Christian belief as such. ${ }^{59}$ Attempting to develop a 'nontrivial test for determining when we get a defeater' for Christian beliefs, he suggests on the basis of his A/C model of faith that, first, if this model applies, faith has a warrant at least as strong as perceptual beliefs, which often function as intrinsic neutralizers of defeaters, and, second, that biblical beliefs can only be defeated by Simonian science if 'there are other perfectly plausible ways of construing' the relevant biblical passage ${ }^{60}$ For clearly, if God is the ultimate author of the Bible, as Plantinga holds, everything contained in it must be true, if properly interpreted.

56 Plantinga (2011: 171-173).

57 Plantinga (2011: 167-8).

${ }^{58}$ Plantinga (2011: 177). Cf. p. 189: 'The mere existence of Simonian science - science that comes to conclusions incompatible with tenets of the Christian faith - has no tendency to produce a defeater for those tenets.'

59 Plantinga (2011: 144, note 23, cf. 10).

${ }^{60}$ Plantinga (2011: 186, 188). 
One should admit to Plantinga that if the Christian god exists, $\mathrm{He}$ might have infused Christian believers with the full panoply of Christian belief, and one might admit for the sake of argument that if believers really acquired their beliefs by such an Internal Instigation of the Holy Spirit (IIHS), this alleged source of knowledge might be - like sense perception is - an intrinsic neutralizer of many defeaters. ${ }^{61}$ But these two 'ifs' are crucial. By calling the background beliefs with reference to which we assess the prior probability of theories, the 'evidence base', and by claiming that the evidence base of the Simonian scientist is simply a sub-set of the evidence base of Christians, because the former is restricted by methodological naturalism, Plantinga suggests that all these background beliefs have the same legitimate status, and that the two 'ifs' are satisfied.

However, as I argued above (\$3), naturalism is not an arbitrary methodological restriction of our scientific evidence base. Rather, it is supported by a convincing consilience of inductions drawn from science in the past. Furthermore, disputed factual background beliefs can legitimately belong to our evidence base only if they result from validated sources of knowledge, as rule $\mathrm{R}$ says. Hence, Plantinga's view that Simonian science 'has no tendency to produce a defeater' for tenets of Christian faith would be correct only if these tenets are really produced by divine grace, or by an IIHS, that is, if at least these two 'ifs' are satisfied. ${ }^{62}$ In order to know that the view is correct, one would have to show that such basic beliefs are properly basic by validating their source of knowledge. Only if this can be done will religious believers not violate rule $\mathrm{R}$ (cf. question 2). ${ }^{63}$

But how might one validate an alleged divine grace or IIHS? Let me consider three possible methods of validation. First, if the Christian god exists, he might have infused with the full panoply of Christian belief tribes of which one can show that they were never influenced, directly or indirectly, by intercultural contacts with Christianity. If anthropologists found such a tribe, and if this tribe endorsed the full panoply of Christian belief, a secular explanation of their beliefs would have a much lower likelihood than the Christian explanation, and this might validate Plantinga's model to some extent. But the immense

${ }^{61}$ Cf. for an argument against this latter claim: Philipse (2012), $\$ 4.3$.

${ }^{62}$ Cf. Plantinga (2011: 189).

${ }^{63}$ The validation requirement of rule $\mathrm{R}$ is internalistic in the epistemological sense, whereas Plantinga's model of religious knowledge is externalistic. 
amount of anthropological research, done during the last four centuries, has not yielded such a result. Second, one might test whether alleged divine grace infuses people of different cultures with the same messages, such as polytheistic Hindus and Mormons. Clearly, this is not the case, and the messages often contradict each other, unless one relativizes them drastically à la John Harwood Hick. ${ }^{64}$ Third, one might validate an alleged IIHS by showing on the basis of public evidence that, probably, the Christian god exists, so that, probably, the A/C model applies. However, Plantinga correctly holds that this cannot be done, even though he avers that the argument from fine-tuning may 'offer non-negligible evidence for theistic belief' ${ }^{65}$ It follows that Plantinga's model of religious knowledge acquisition has not been, and probably cannot be, validated.

The deep conflict between science and religion (\$3) amounts to the de jure objection against religious believers that, to the extent that they endorse positive factual claims to truth concerning the supernatural, the sources of their beliefs have not been validated, so that they violate rule R. Since this de jure objection also applies to Plantinga's hypothetical A/C \& IIHS model of religious belief, and does not depend upon the de facto objection that the Christian god does not exist, Plantinga's religious epistemology does not resolve the profound conflict between science and religion. ${ }^{66}$

\section{BIBLIOGRAPHY}

Beatty, J. 2006. 'Chance Variation: Darwin on Orchids', Philosophy of Science, 73 (5): 629-641

Beilby, James K., ed. 2002. Naturalism Defeated? Essays on Plantinga's Evolutionary Argument against Naturalism (New York: Cornell University Press)

Boudry, Maarten. 2012. 'Review of Alvin Plantinga, Where the Conflict Really Lies. Science, Religion and Naturalism (2011)', Sci \& Educ, DOI 10.1007/ s11191-012-9516-y

${ }^{64}$ Cf., for example, Hick (1982). Plantinga disagrees with Hick's relativism: (Plantinga 2000: 438 ff.).

${ }^{65}$ Plantinga (2011: xiii).

${ }^{66}$ I would like to thank Nick Boerma, Maarten Boudry, Kelly James Clark, Peter Hacker, Stefan Paas, Rik Peels, Alvin Plantinga, Tyler Wunder, and the members of the Dutch National Seminar for Analytic Philosophy, for their helpful comments on an earlier version of this paper. Parts of this paper were originally presented in Berlin (Katholische Akademie, March 15, 2013), at a workshop for the Analytic Theology Project, generously funded by the John Templeton Foundation. 
Boudry, Maarten, Stefaan Blancke, and Johan Braeckman. 2010. 'How Not to Attack Intelligent Design Creationism: Philosophical Misconceptions About Methodological Naturalism, Found Sci, 12: 227-244

Bowler, Peter J. 1989. Evolution. The History of an Idea, Revised Edition (Berkeley and Los Angeles: University of California Press)

Childers, Geoff. 2011. 'What's Wrong with the Evolutionary Argument Against Naturalism?', International Journal for Philosophy of Religion, 69: 193-204

Coyne, Jerry A. 2009. 'Seeing and Believing', New Republic, February 4. Retrieved from <http://www.tnr.com/article/books/seeing-and-believing?page=2> [accessed 13/06/2013]

Darwin, Charles. 1859. The Origin of Species, ed. by Gillian Beer in Oxford World's Classics (Oxford: Oxford University Press, 1996)

Darwin, Charles. 1868. The Variation of Animals and Plants Under Domestication (New York: Appleton, $2^{\text {nd }}$ edition, 1876)

Dobzhansky, T., F. J. Ayala, G. L. Stebbins, and J. W. Valentine. 1977. Evolution (San Francisco: WH Freeman \& Company)

Fales, Evan. 1996. 'Plantinga's Case against Naturalistic Epistemology', Philosophy of Science, 63 (3): 432-451

Fisher, R. A. 1999 [1930]. The Genetical Theory of Natural Selection: a Complete Variorium Edition (Oxford: Oxford University Press)

Gould, Stephen Jay. 1999. Rocks of Ages: Science and Religion in the Fullness of Life (New York: Norton)

Hacking, Ian. 1983. Representing and Intervening. Introductory Topics in the Philosophy of Natural Science (Cambridge: Cambridge University Press)

Hahn, Roger. 2005. Pierre Simon Laplace, 1749-1827. A Determined Scientist (Cambridge, Mass.: Harvard University Press)

Hick, John. 1982. God Has Many Names (Louisville: Westminster John Knox Press)

Hodge, Charles. 1871. What is Darwinism? (New York: Charles Scribner)

Jackson, Patrick Wyse. 2006. The Chronologers' Quest. The Search for the Age of the Earth (Cambridge: Cambridge University Press)

Kvanvig, Jonathan L., ed. 2011. Oxford Studies in Philosophy of Religion, Vol. 3 (Oxford: Oxford University Press)

Law, Stephen. 2012. 'Naturalism, Evolution and True Belief', Analysis, 72 (1): 41-48

Mayr, Ernst. 1988. Towards a New Philosophy of Biology: Observations of an Evolutionist (Cambridge, Mass.: Harvard University Press)

Mayr, Ernst. 2001. What Evolution Is (Phoenix paperback edition. London: Orion Books Ltd, 2002)

Merlin, Francesca. 2010. 'Evolutionary Chance Mutation: A Defense of the Modern Synthesis' Consensus View', Philos. Theor. Biol., 2: 103. 
Monton, Bradley, and Logan Paul Gage. 2012. 'Alvin Plantinga: Where the Conflict Really Lies: Science, Religion, and Naturalism', Int. J. Philos. Relig., 72: 53-57

Moser, Paul K. 2010. The Evidence for God. Religious Knowledge Reexamined (Cambridge: Cambridge University Press)

Nilsson, D.E., \& S. Pelger. 1994. 'A Pessimistic Estimate of the Time Required for an Eye to Evolve', Proceedings of the Royal Society of London, Series B: Biol. Sciences, 256 (1345): 53-8

Philipse, Herman. 2012. God in the Age of Science? A Critique of Religious Reason (Oxford: Oxford University Press)

Phillips, D. Z. 2005. 'Wittgensteinianism: Logic, Reality and God', Chapter 18 of The Oxford Handbook of Philosophy of Religion, edited by William J. Wainwright (Oxford: Oxford University Press), pp. 447-471

Plantinga, Alvin. 1982. 'The Reformed Objection to Natural Theology', Christian Scholar's Review, 11 (3): 187-98

Plantinga, Alvin. 2000. Warranted Christian Belief (Oxford \& New York: Oxford University Press)

Plantinga, Alvin. 2011. Where the Conflict Really Lies. Science, Religion, and Naturalism (Oxford: Oxford University Press)

Plantinga, Alvin, and Michael Tooley. 2008. Knowledge of God (Oxford: Blackwell)

Ridley, Mark. 2004. Evolution, Third Edition (Oxford: Blackwell)

Rowbottom, Darrell P. 2010. 'Evolutionary Epistemology and the Aim of Science, Australasian Journal of Philosophy, 88 (2): 209-225

Simpson, George Gaylord. 1984 [1944]. Tempo and Mode in Evolution (New York: Columbia University Press)

Sober, Elliott. 2010. 'Evolution without Naturalism', in J. Kvanvig (ed.), Oxford Studies in Philosophy of Religion, Vol. 3 (Oxford: Oxford University Press), pp. 187-222

Sober, Elliott. 2011. Did Darwin Write the Origin Backwards? Philosophical Essays on Darwin's Theory (Amherst, NY: Prometheus Books)

Sober, Elliott. Forthcoming. 'Evolutionary Theory, Causal Completeness, and Theism: the Case of "Guided" Mutations', To be published in D. Walsh and P. Thompson (eds.), Essays in Honour of Michael Ruse (Cambridge: Cambridge University Press)

Swinburne, Richard. 2004. The Existence of God, Second Edition (Oxford: Oxford University Press)

Worrall, John. 2000. 'Science Discredits Religion', in Contemporary Debates in Philosophy of Religion, ed. M. Peterson and R. Van Arragon (Oxford: Blackwell), pp. 59-72 